\title{
Densitometric and Ratio Spectra Methods for Simultaneous Determination of Sulfaquinoxaline Sodium and Pyrimethamine in Binary Mixture
}

\author{
Original \\ Article \\ Sawsan A. Abdel Razeq ${ }^{1}$, Asmaa O. El Demerdash', Manal M. Fouad ${ }^{1,2}$, and \\ Hoda F. El Sanabary
}

${ }^{1}$ Analytical Chemistry Department, Faculty of Pharmacy (Girls), Al-Azhar University

${ }^{2}$ Faculty of Pharmacy, October University for Modern Sciences and Arts (MSA)

${ }^{3}$ National Organization for Drug Control and Research (NODCAR)

\begin{abstract}
Four methods were developed for simultaneous determination of sulfaquinoxaline-Na and pyrimethamine in their combined pharmaceutical formulations. The first one was a densitometric method where chloroform-methanol (9: 1, v/v) was the developing system and the plates were scanned at $254 \mathrm{~nm}$. The obtained spots appeared at Rf 0.64 and 0.35 and determined in the range of $0.5-10.0 \mu \mathrm{g} / \mathrm{spot}$ and $0.1-10.0 \mu \mathrm{g} / \mathrm{spot}$ for sulfaquinoxaline-Na and pyrimethamine, respectively. Furthermore, three spectrophotometric methods manipulating ratio spectra namely, ratio difference method, extended ratio subtraction method coupled with ratio subtraction method and mean centering method were established for the determination of the two studied drugs in the presence of propylene glycol as a solvent. Linear correlation was found over the concentration range of 2-25 $\mu \mathrm{g}$ mL-1 and 3-15 $\mu \mathrm{g} \mathrm{mL}-1$ for the two drugs, respectively. The proposed methods were successfully applied for analyzing the cited drugs in their veterinary pharmaceutical formulations. The obtained results were statistically analyzed and found to be in accordance with those given by a reported method. The validity of the methods was evaluated according to ICH guidelines.
\end{abstract}

Received: 16 January 2019, Accepted: 26 June 2019

Key Words: Mean centering, pyrimethamine, ratio difference, ratio subtraction, sulfaquinoxaline-Na.

Corresponding Author: Asmaa O. El Demerdash, PhD., Faculty of Pharmacy for Girls, Al-Azhar University, Al- Nasr Road, opposite to Cairo International Conference Center, Nasr City, Cairo P.O Box: 11751, Egypt, Tel.: +20 1282958742, Fax: +2 02 224018119, Fax: +2 02 24018031, E-mail: othman-asmaa@hotmail.com

Bulletin of Faculty of Pharmacy, Cairo University, ISSN: 1110-0931, Vol. 57, No. 1

\section{INTRODUCTION}

Sulfaquinoxaline-Na, N 4-Amino-N-quinoxalin-2ylbenzenesulfonamide sodium salt ${ }^{[1,2]}$. It is a bacteriostatic sulfonamide used in veterinary medicine as coccidiostat ${ }^{[3]}$ which acts by interfering with the biosynthesis of folic acid in bacterial cells ${ }^{[1]}$; Figure 1a. Pyrimethamine is a
5-(4-Chlorophenyl)-6-ethylpyrimidine-2,4-diamine. It is a dihydro- folate reductase inhibitor used as antiprotozoal in the treatment of malaria ${ }^{[1-3]}$. A combination of both drugs is used in the poultry industry to effectively combat coccidiosis $^{[1,2]}$; Figure 1a. (a)<smiles>Nc1ccc(S(=O)(=O)N([AlH2])c2cnc3ccccc3n2)cc1</smiles><smiles>CCc1nc(N)nc(N)c1-c1ccc(Cl)cc1</smiles>

Fig. 1: Chemical structure of (a) sulfaquinoxaline-Na and (b) pyrimethamine 
Several analytical methods have been reported for the determination of either sulfaquinoxaline$\mathrm{Na}$ or pyrimethamine in their pharmaceutical formulations and/or in biological fluids. The literature comprises spectrophotometric ${ }^{[4-8]}$, electrochemical ${ }^{[9-12]}$, biochemical ${ }^{[13-15]}$ and chromatographic techniques namely, densitometry ${ }^{[16-19]}, \mathrm{GC}^{[20-22]}$ and HPLC ${ }^{[23-29]}$. Also, capillary electrophoresis ${ }^{[30-32]}$ was revealed for sulfaquinoxaline$\mathrm{Na}$ determination. It was noticed that the only analytical methods have been described in the literature for the simultaneous determination of sulfaquinoxaline- $\mathrm{Na}$ and pyrimethamine in mixture were the first derivative of the ratio spectra ${ }^{[33,34]}$ and HPLC ${ }^{[35-37]}$.

The aim of the present study is to develop simple, sensitive, selective and accurate densitometric and UV-spectrophotometric methods for the simultaneous determination of sulfaquinoxaline-Na and pyrimethamine in their pharmaceutical formulations.

\section{EXPERIMENTAL}

\subsection{Instruments}

- Densitometer model 3; equipped with WinCats software, Camag TLC scanner 3, Camag lincomat 5 autosampler.

- UV-Vis spectrophotometer (Shimadzu 1601, Japan).

- Thin layer chromatographic plates pre-coated with silica gel 60 F254, 10x20 cm (Merck, Germany).

\subsection{Materials and Reagents}

- Pure sulfaquinoxaline-Na, B. N. BL130602, was kindly supplied by Unipharma Company, Egypt with purity of $99.5 \%$ as referred by the supplier.

- $\quad$ Pure pyrimethamine, B.N. 120070108, was kindly supplied by Copad Pharma, Egypt; 99.8\% purity as referred by the supplier.

- Sodicoc-oral solution (1 Liter); B.N. 0152163, labeled to contain $46.6 \mathrm{mg}$ of sulfaquinoxaline-Na and $15 \mathrm{mg}$ of pyrimethamine per $\mathrm{mL}$, the product of Biovet, Egypt; was purchased from a local market.

- Thiamincox-oral solution (1 Liter); B.N. 60450, labeled to contain $34.88 \mathrm{mg}$ of sulfaquinoxaline$\mathrm{Na}$ and $9.8 \mathrm{mg}$ of pyrimethamine per $\mathrm{mL}$, the product of Medizen Pharmaceutical Industry, Egypt; was purchased from a local market.

- Methanol, HPLC grade (Scharlau chemie, Spain).

- Chloroform, HPLC grade (Honil Limited, London, UK).

- $\quad$ Propylene glycol, (Adwic. Cairo, Egypt).

\subsection{Standard solutions}

Five mg mL-1 solution of sulfaquinoxaline- $\mathrm{Na}$ and two mg mL-1 solution of pyrimethamine were prepared separately in methanol to be used by the densitometric method. For the UV-spectrophotometric methods, stock solutions of the two drugs $(0.1 \mathrm{mg} \mathrm{mL}-1)$ were prepared by dissolving $10 \mathrm{mg}$ of sulfaquinoxaline-Na or pyrimethamine in $100 \mathrm{~mL}$ propylene glycol.

\subsection{Procedures}

\subsubsection{Linearity}

\subsubsection{Densitometric method}

The TLC plates pre-coated with silica gel 60 F254 $(10 \times 20 \mathrm{~cm})$ were loaded with ten $\mu \mathrm{L}$ of each solution at the baseline. The plates were spotted $1 \mathrm{~cm}$ apart from each other and $2 \mathrm{~cm}$ apart from the bottom edge. The chromatographic chamber was pre-saturated for 30 minutes with the mobile phase. Ascending development process was performed with a mobile phase of chloroform: methanol $(9: 1, \mathrm{v} / \mathrm{v})$ through a distance of $7 \mathrm{~cm}$ at room temperature then the plates were left to dry in air. The spots finally were scanned at $254 \mathrm{~nm}$ and the areas under the peaks were recorded against each drug concentration and the regression equations were calculated.

\subsubsection{Spectrophotometric methods}

Accurately measured aliquots of sulfaquinoxaline$\mathrm{Na}$ or pyrimethamine standard solutions in propylene glycol $(0.1 \mathrm{mg} \mathrm{mL}-1)$ equivalent to $0.02-0.25 \mathrm{mg}$ or 0.03-0.15 mg, respectively; were separately dissolved in $10-\mathrm{mL}$ propylene glycol. The prepared solutions were scanned over the range of $200-400 \mathrm{~nm}$ and the zero-order spectra were stored in the computer. The ratio spectra of sulfaquinoxaline-Na were calculated using $10 \mu \mathrm{g} \mathrm{mL}-1$ pyrimethamine as a divisor in case of the ratio difference and the extended ratio subtraction methods or $3 \mu \mathrm{g} \mathrm{mL}-1$ pyrimethamine for the mean centering method. Whereas pyrimethamine ratio spectra were obtained upon dividing its spectra by $20 \mu \mathrm{g} \mathrm{mL}-1$ sulfaquinoxaline-Na to be used by all the proposed methods

\subsection{Ratio difference (RD) method}

The calibration curves of the two drugs were constructed by plotting the difference between the amplitudes of the obtained ratio spectra at 251 and 297 $\mathrm{nm}$ for sulfaquinoxaline-Na or between 297 and 280 $\mathrm{nm}$ for pyrimethamine versus the corresponding drug concentration. Then, the regression equation of each drug was computed.

\subsection{Extended ratio subtraction (EXRS) coupled with ratio subtraction (RS) method}

The absorbance of the zero-order spectra of sulfaquinoxaline- $\mathrm{Na}$ at 250 and $267 \mathrm{~nm}$ or those of pyrimethamine at $288 \mathrm{~nm}$ were linearly recorded against the corresponding concentration from which the regression equations were deduced.

\subsection{Mean centering (MC) method}

From the stored data, the ratio spectra were firstly mean 
centered using MATLAB R2017b software. Subsequently, the amplitude of the resultant mean centered peaks was measured at 223 and $299 \mathrm{~nm}$ and plotted against the corresponding sulfaquinoxaline-Na concentrations to get its regression equations. The same procedure was followed for pyrimethamine to be quantified and the regression equation was obtained from the calibration curve representing the peak amplitude at $223 \mathrm{~nm}$ against pyrimethamine concentrations.

\subsubsection{Assay of laboratory prepared mixtures of the two drugs}

\subsubsection{Densitometric method}

Into a set of $10-\mathrm{mL}$ volumetric flasks, aliquots of standard sulfaquinoxaline-Na solution $(5 \mathrm{mg} \mathrm{mL}-1)$ equivalent to 0.5-10.0 $\mathrm{mg}$ drug were mixed with different volumes of standard pyrimethamine ( $2 \mathrm{mg} \mathrm{mL}-1$ ) containing $0.1-10.0$ $\mathrm{mg}$ pure drug. Volumes were completed to the mark with methanol and the prepared mixtures were then analyzed by densitometry as described under "2.4.1. Linearity".

\subsubsection{Spectrophotometric methods}

Aliquots of standard drugs solutions $(0.1 \mathrm{mg} \mathrm{mL}-1)$ equivalent to $0.02-0.25 \mathrm{mg}$ sulfaquinoxaline- $\mathrm{Na}$ and 0.03 $0.15 \mathrm{mg}$ pyrimethamine were mixed in a series of $10-\mathrm{mL}$ volumetric flasks. Volumes were completed with propylene glycol and the zero-order spectra of the mixtures were recorded at $200-400 \mathrm{~nm}$. The ratio spectra of the laboratory prepared mixtures were obtained following the abovementioned procedures detailed under "2.4.1. Linearity". The concentration of each drug was calculated by substitution in the corresponding regression equation after applying the corresponding manipulating steps described under "2.4.1. Linearity" for the ratio difference and mean centering methods. However, the following procedures should be applied in case of the ratio subtraction and the extended ratio subtraction methods:

On one hand, the ratio subtraction method was performed for pyrimethamine estimation. A plateau region (205-215 nm) was observed in the ratio spectra of the laboratory prepared mixtures. The amplitude of this plateau region was recorded and then subtracted from those laboratory prepared mixtures ratio spectra. Then, upon multiplying the obtained spectra by $20 \mu \mathrm{g} \mathrm{mL}-1$ sulfaquinoxaline-Na', pyrimethamine zero-order spectrum was obtained and accordingly its concentration in each mixture was calculated from the corresponding regression equation at $288 \mathrm{~nm}$.

On the other hand, sulfaquinoxaline-Na could be estimated by applying the extended ratio subtraction. Firstly, the constant value at the plateau area should be calculated. It was done by dividing the spectrum of standard pyrimethamine of the same concentration that is found in the laboratory prepared mixture by the selected devisor 10 $\mu \mathrm{g}$ mL-1 pyrimethamine'. Again, this plateau value would be subtracted from the corresponding ratio spectrum of the laboratory prepared mixture. Finally, the obtained spectrum was multiplied by $10 \mu \mathrm{g} \mathrm{mL}-1$ pyrimethamine where sulfaquinoxaline-Na zero-order spectrum would result. Sulfaquinoxaline-Na concentration in each mixture was calculated at 250 and $267 \mathrm{~nm}$ using its corresponding regression equations.

\subsubsection{Application to pharmaceutical formulations}

The contents of five Sodicoc-oral solutions were thoroughly mixed. A volume equivalent to $466 \mathrm{mg}$ sulfaquinoxaline- $\mathrm{Na}$ and $150 \mathrm{mg}$ pyrimethamine was transferred into $100-\mathrm{mL}$ volumetric flask and volume was completed with methanol to obtain a clear solution labeled to contain $4.66 \mathrm{mg} \mathrm{mL}-1$ sulfaquinoxaline-Na and 1.50 $\mathrm{mg} \mathrm{mL}-1$ pyrimethamine to be analyzed by the proposed densitometric method. For the spectrophotometric methods, five $\mathrm{mL}$ of Sodicoc solution equivalent to 23.30 $\mathrm{mg}$ sulfaquinoxaline- $\mathrm{Na}$ and $7.50 \mathrm{mg}$ pyrimethamine were dissolved in $100-\mathrm{mL}$ propylene glycol to prepare a solution claimed to contain $0.233 \mathrm{mg} \mathrm{mL}-1$ sulfaquinoxaline-Na and $0.075 \mathrm{mg} \mathrm{mL}-1$ pyrimethamine.

Similarly, the contents of five Thiamincox-oral solutions were treated as previously mentioned to obtain two solutions; the first labeled to contain $3.488 \mathrm{mg} \mathrm{mL}-1$ sulfaquinoxaline- $\mathrm{Na}$ and $0.98 \mathrm{mg} \mathrm{mL}-1$ pyrimethamine in methanol while the other claimed to contain 0.1744 $\mathrm{mg} \mathrm{mL}-1$ sulfaquinoxaline-Na and $0.049 \mathrm{mg} \mathrm{mL}-1$ pyrimethamine in propylene glycol. These two sample solutions were analyzed for assay determination by the suggested densitometric and spectrophotometric methods, respectively.

For each proposed method, the details under "2.4.1. Linearity" and "2.4.2. Assay of laboratory prepared mixtures of the two drugs" were followed and the concentration of each drug was calculated from the corresponding regression equation.

Upon carrying out the standard addition technique, either Sodicoc solution or Thiamincox solution was mixed well with different portions of pure sulfaquinoxaline-Na and pyrimethamine solutions before proceeding in the above-mentioned procedures.

\section{RESULTS AND DISCUSSION}

\subsection{Densitometric method}

Literature survey revealed the lack of any densitometric method for sulfaquinoxaline-Na determination either alone or in the presence of pyrimethamine. Several developing systems with different ratios were tried, such as ethyl acetate-dichloromethane $(8: 2, \mathrm{v} / \mathrm{v})$, ethyl acetate-methanol $(9: 1, \mathrm{v} / \mathrm{v})$, chloroform-ethyl acetate-methanol $(5: 5: 1, \mathrm{v} / \mathrm{v} / \mathrm{v})$, chloroform-toluene-methanol $(6: 5: 3, \mathrm{v} / \mathrm{v} / \mathrm{v})$; none of them fulfill the purpose. Best resolution of sulfaquinoxaline-Na and pyrimethamine was achieved using a mobile phase of chloroform- methanol $(9: 1, \mathrm{v} / \mathrm{v})$ where the Rf values were found to be 0.64 and 0.35 , respectively. Based on this difference in $\mathrm{Rf}$ values, the chromatogram of the two drugs were measured densitometrically at $254 \mathrm{~nm}$; Figure 2. 


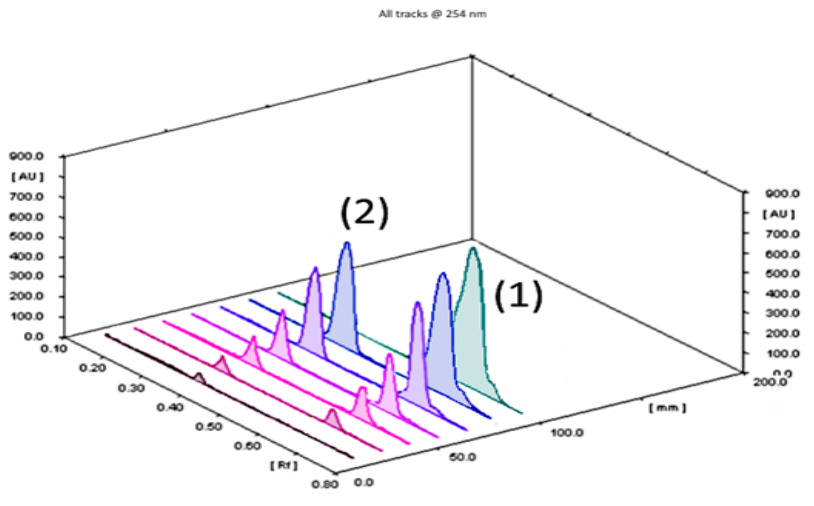

Fig. 2: Densitometric chromatogram of (1) sulfaquinoxaline-Na (0.5 - 10 $\mu \mathrm{g} / \mathrm{spot})$ and (2) pyrimethamine $(0.1-10 \mu \mathrm{g} / \mathrm{spot})$.

\subsection{Spectrophotometric methods}

It was noticed that almost the commercially available veterinary formulations containing sulfaquinoxaline- $\mathrm{Na}$ and pyrimethamine combination had been formulated using propylene glycol as a solvent. Propylene glycol has an absorption band at $240 \mathrm{~nm}$ where high interference with the already overlapped spectra of the two cited drugs was observed. A problem that had hindered their quality control analysis spectrophotometrically; Figures 3 and 4. Another problem was the presence of the excipients $\mathrm{N}$-methyl pyrrolidone and dimethyl formamide in Sodicoc solution which absorb at $217 \mathrm{~nm}$ where additional overlap was found. Consequently, three spectrophotometric methods manipulating ratio spectra were developed namely, ratio difference method, extended ratio subtraction coupled with ratio subtraction method and mean centering method where propylene glycol was the solvent. It is noteworthy to mention that all the established methods could be applied successfully to solve the spectral overlap of the two cited drugs in the presence of propylene glycol together with the above-mentioned excipients beyond the mean centering method that failed to reveal the excipients spectral overlap.

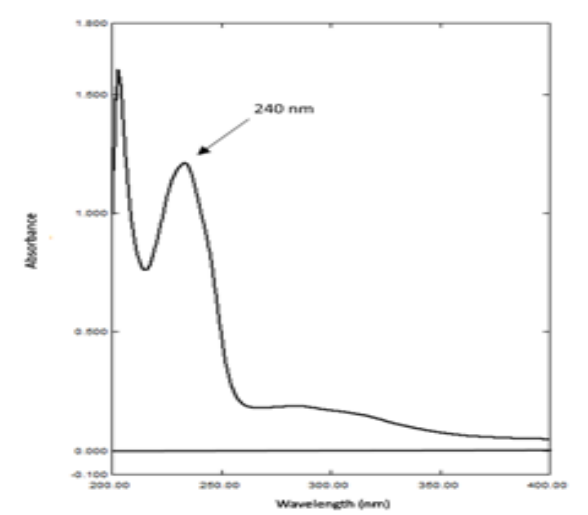

Fig.3: Absorption spectrum of propylene glycol against ethanol as a blank.

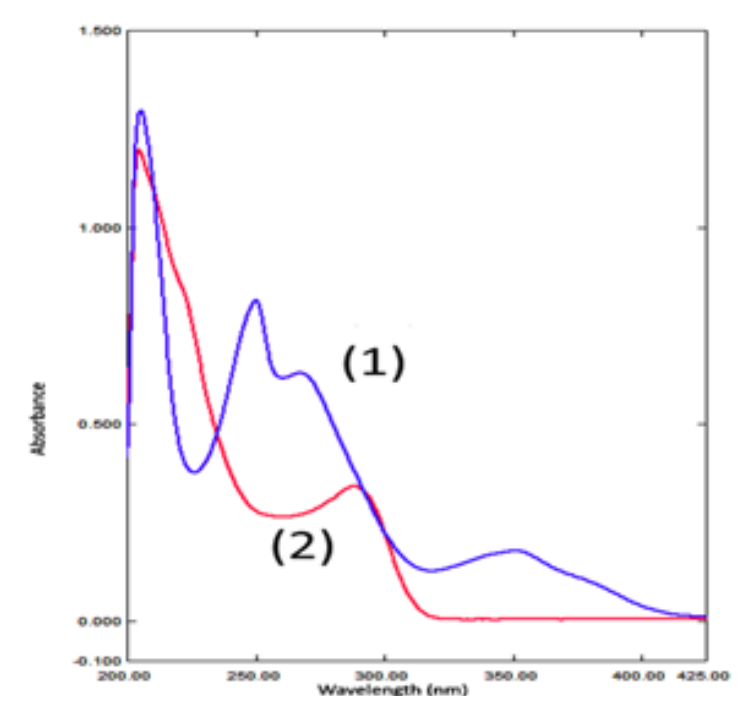

Fig. 4: Absorption spectra of (1) sulfaquinoxaline-Na $10 \mu \mathrm{g} \mathrm{mL}^{-1}$ and (2) pyrimethamine $10 \mu \mathrm{g} \mathrm{mL}^{-1}$ in propylene glycol.

In addition, there are two common factors should be taken into consideration when applying methods manipulating ratio spectra. The first one is the choice of a divisor which should provide minimal noise with maximum sensitivity. The second one is the choice of the wavelengths that exhibit different amplitudes in the ratio spectrum besides showing a linear relationship at each wavelength $^{[38,39]}$.

\subsubsection{Ratio difference (RD) method}

This method depends on measuring the difference in amplitudes in the ratio spectra at which linear correlation was observed. Likewise, the devisor concentration yielding a superior signal to noise ratio was studied. On these bases, sulfaquinoxaline-Na was determined using 10 $\mu \mathrm{g} \mathrm{mL}-1$ pyrimethamine as a divisor where the selected amplitudes were at 251 and $297 \mathrm{~nm}$. Similarly, the selected wavelengths for the estimation of pyrimethamine using standard sulfaquinoxaline-Na $(20 \mu \mathrm{g} \mathrm{mL}-1)$ as a divisor were 297 and $280 \mathrm{~nm}$; Figures 5 and 6.

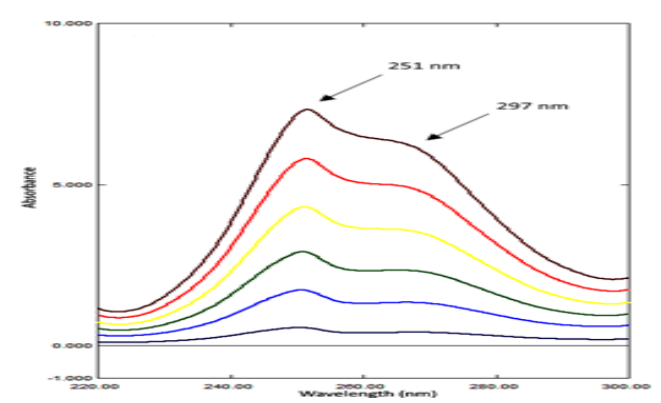

Fig. 5: Ratio spectra of sulfaquinoxaline-Na $\left(2-25 \mu \mathrm{g} \mathrm{mL}^{-1}\right)$ using $10 \mu \mathrm{g}$ $\mathrm{mL}^{-1}$ pyrimethamine as a devisor. 


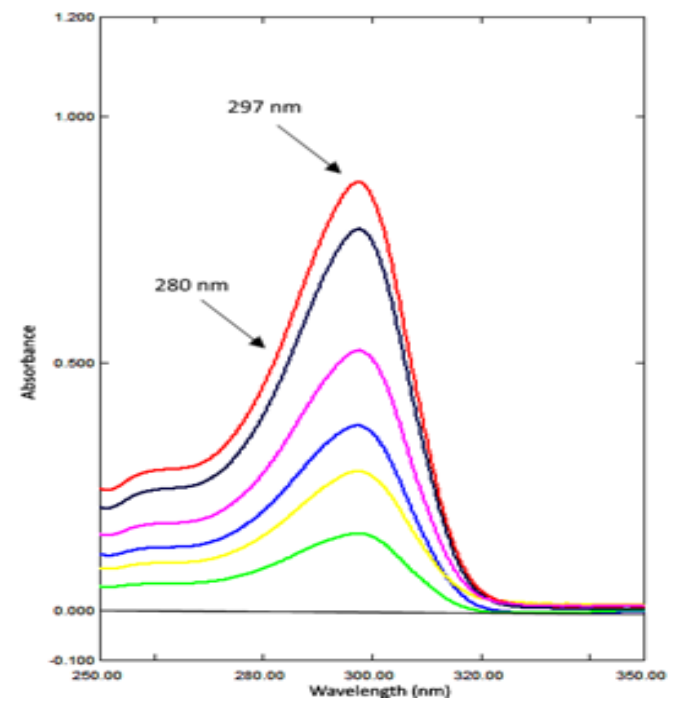

Fig. 6: Ratio spectra of pyrimethamine (3-15 $\left.\mu \mathrm{g} \mathrm{mL}^{-1}\right)$ using $20 \mu \mathrm{g} \mathrm{mL}^{-1}$ sulfaquinoxaline-Na as a devisor.

\subsubsection{Extended ratio subtraction (EXRS) method coupled with ratio subtraction (RS) method}

The two methods are integral due to their ability to evaluate the two target compounds in the mixture. Both methods are based on subtraction of the plateau values from the ratio spectrum of each drug. Then, the obtained spectrum would be multiplied by the corresponding devisor to be converted into its original zero-order one which is directly used for the drug determination from its corresponding regression equation.

\subsubsection{Mean centering (MC) method}

This method merely depended on mean centering of ratio spectra. Different concentrations of pyrimethamine were tried as a divisor for sulfaquinoxaline-Na determination, and only pyrimethamine $3 \mu \mathrm{g}$ mL-1 was found to be the most suitable one as it gave higher and welldefined analytical signals of sulfaquinoxaline-Na. While pyrimethamine determination was conducted using 20 $\mu \mathrm{g}$ mL-1 sulfaquinoxaline-Na as a divisor which provide maximum selectivity. Mean-centering of the ratio spectra was obtained in the wavelength range of $200-350 \mathrm{~nm}$ for sulfaquinoxaline-Na or $200-400 \mathrm{~nm}$ for pyrimethamine; Figures 7 and 8 . The concentration of sulfaquinoxaline$\mathrm{Na}$ and pyrimethamine was determined by measuring the mean centered peak amplitude at 223 and $299 \mathrm{~nm}$ for the former and at $223 \mathrm{~nm}$ for the latter. Unfortunately, pyrimethamine could not be determined at $298 \mathrm{~nm}$ due to unreliable results.

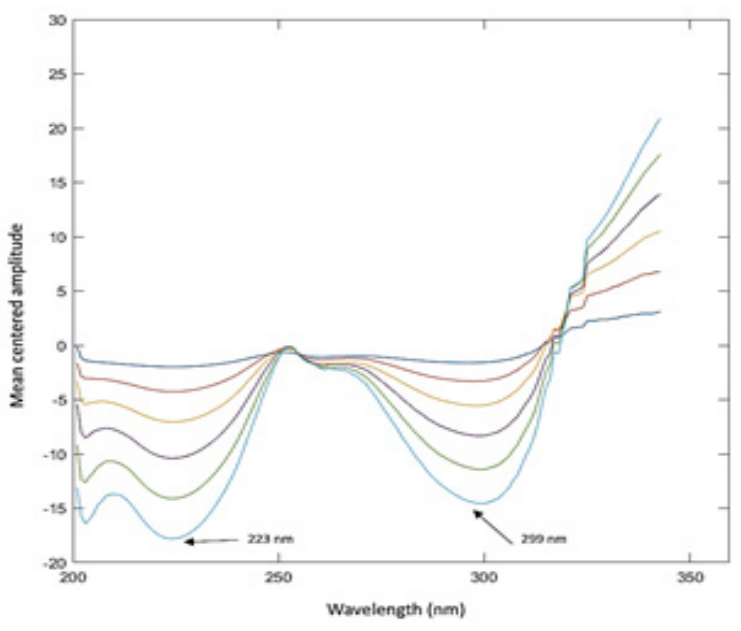

Fig. 7: Mean centered ratio spectra of sulfaquinoxaline- $\mathrm{Na}$ (2-25 $\left.\mu \mathrm{g} \mathrm{mL}^{-1}\right)$ using $3 \mu \mathrm{g} \mathrm{mL}^{-1}$ pyrimethamine as a devisor.

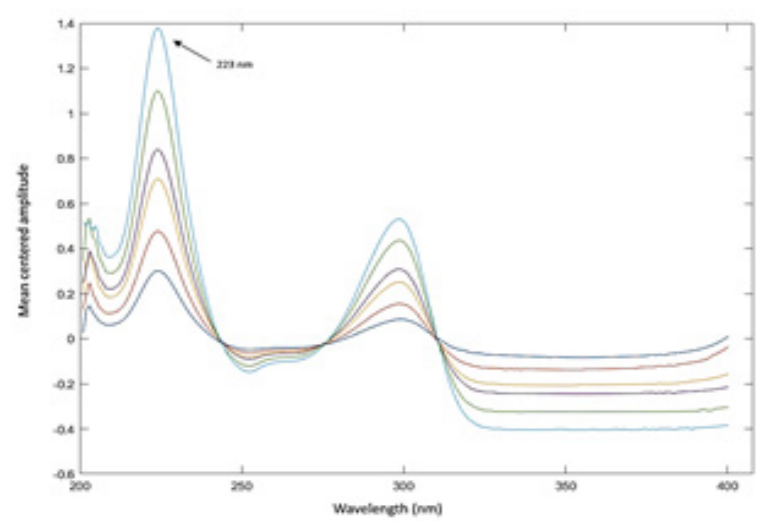

Fig. 8: Mean centered ratio spectra of pyrimethamine $\left(3-15 \mu \mathrm{g} \mathrm{mL}^{-1}\right)$ using $20 \mu \mathrm{g} \mathrm{mL}^{-1}$ sulfaquinoxaline-Na as a devisor.

\subsection{Method validation}

The proposed methods were validated according to ICH guidelines ${ }^{[40]}$.

\subsubsection{Linearity}

The obtained standard curves of the peak areas of the separated spots or the response and the corresponding drug concentration were linear in the ranges of, 0.5$10.0 \mu \mathrm{g} / \mathrm{spot}$ and $0.1-10.0 \mu \mathrm{g} / \mathrm{spot}$ for the densitometric method and 2-25 $\mu \mathrm{g} \mathrm{mL}-1$ and 3-15 $\mu \mathrm{g} \mathrm{mL}-1$ for the spectrophotometric methods regarding sulfaquinoxaline$\mathrm{Na}$ and pyrimethamine, respectively. The regression data were calculated and presented in Table 1 . 


\subsubsection{Accuracy and precision}

The repeatability and the reproducibility of the proposed methods was assured by triplicate analysis of three different concentrations of each drug covering its specified linearity range, within one day and at three different days over a period of two months. The obtained accuracies ranges were 99.62-100.74\% and 99.78-100.50\% with RSD\% amounted to be $0.17-1.70$ and $0.19-1.67$ for sulfaquinoxaline-Na and pyrimethamine, respectively; Table 1 .

\subsubsection{Selectivity}

Sulfaquinoxaline-Na was mixed with pyrimethamine in different ratios $(1: 2,1: 1,2: 1$ and $3: 1$, respectively) and the prepared mixtures were analyzed by the densitometric and spectrophotometric methods. Simultaneous determination of the two drugs without any interference was done. Thus, the established methods were proved to be selective as indicated by recoveries of $99.12-100.65 \% \pm 0.77-1.35$ and $98.77-100.77 \% \pm 0.71-1.18$ for sulfaquinoxaline-Na and pyrimethamine, respectively; Table 2 .

The selectivity of the proposed methods was further evaluated by analyzing the studied drugs in two of their veterinary pharmaceutical formulations; Sodicoc and Thiamincox oral solutions. Satisfactory results had confirmed that both drugs could be simultaneously determined by all the proposed methods without interference from excipients and additives except the mean centering one, Table 3.

Although the mean centering method was employed successfully for determining the two drugs in Thiamincox solution, unfortunately, neither sulfaquinoxaline-Na nor pyrimethamine could be quantitatively estimated at 223 $\mathrm{nm}$ in Sodicoc solution due to the presence of N-methyl pyrrolidone and dimethyl formamide as excipients which are not contained in Thiamincox solution. Nevertheless, sulfaquinoxaline-Na could be determined in Sodicoc solution at the other wavelength $299 \mathrm{~nm}$.

Validity of the proposed methods was further assessed by applying the standard addition technique where the good recoveries of pure drug samples suggest satisfactory accuracy, Table 3 . These results were statistically ${ }^{[41]}$ compared with those obtained from a reported method which is a UV- measurements for the first derivative of the ratio spectra of sulfaquinoxaline-Na at 241 and $271 \mathrm{~nm}$ and pyrimethamine at 290 and $304 \mathrm{~nm}^{[33]}$. As shown in Table 3 , calculated $\mathrm{t}$ - and F-values were less than theoretical ones, indicating that there was no significant difference between the proposed and reported methods. However, the proposed methods were found to be more selective, so that the quantitative estimation of sulfaquinoxaline-Na and pyrimethamine in their combined formulations could be carried out successfully without interference from excipients and additives.

\subsubsection{Stability of standard solutions}

The stability of the methanolic solutions of sulfaquinoxaline-Na (5 mg mL-1) and pyrimethamine ( $2 \mathrm{mg} \mathrm{mL}-1)$ were evaluated by the densitometric method. This was carried out through storing on laboratory bench and in the refrigerator at $4^{\circ} \mathrm{C}$. The solutions were found to be stable for two weeks either at room temperature or in refrigerator. While the stability of the standard solutions of both drugs in propylene glycol $(0.1 \mathrm{mg} \mathrm{mL}-1)$ were evaluated by the spectrophotometric methods and found to be stable for more than one month at room temperature or in refrigerator. 


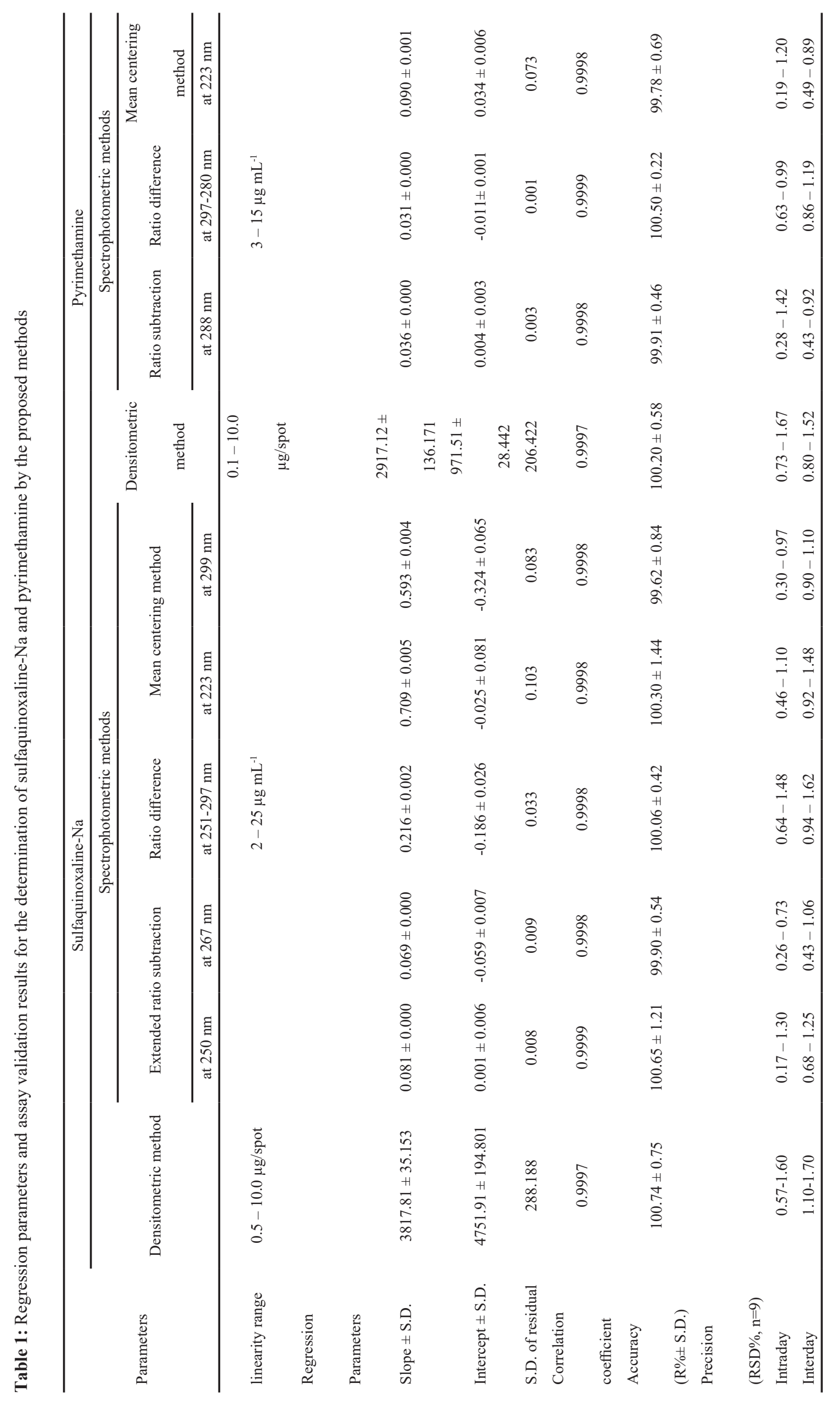




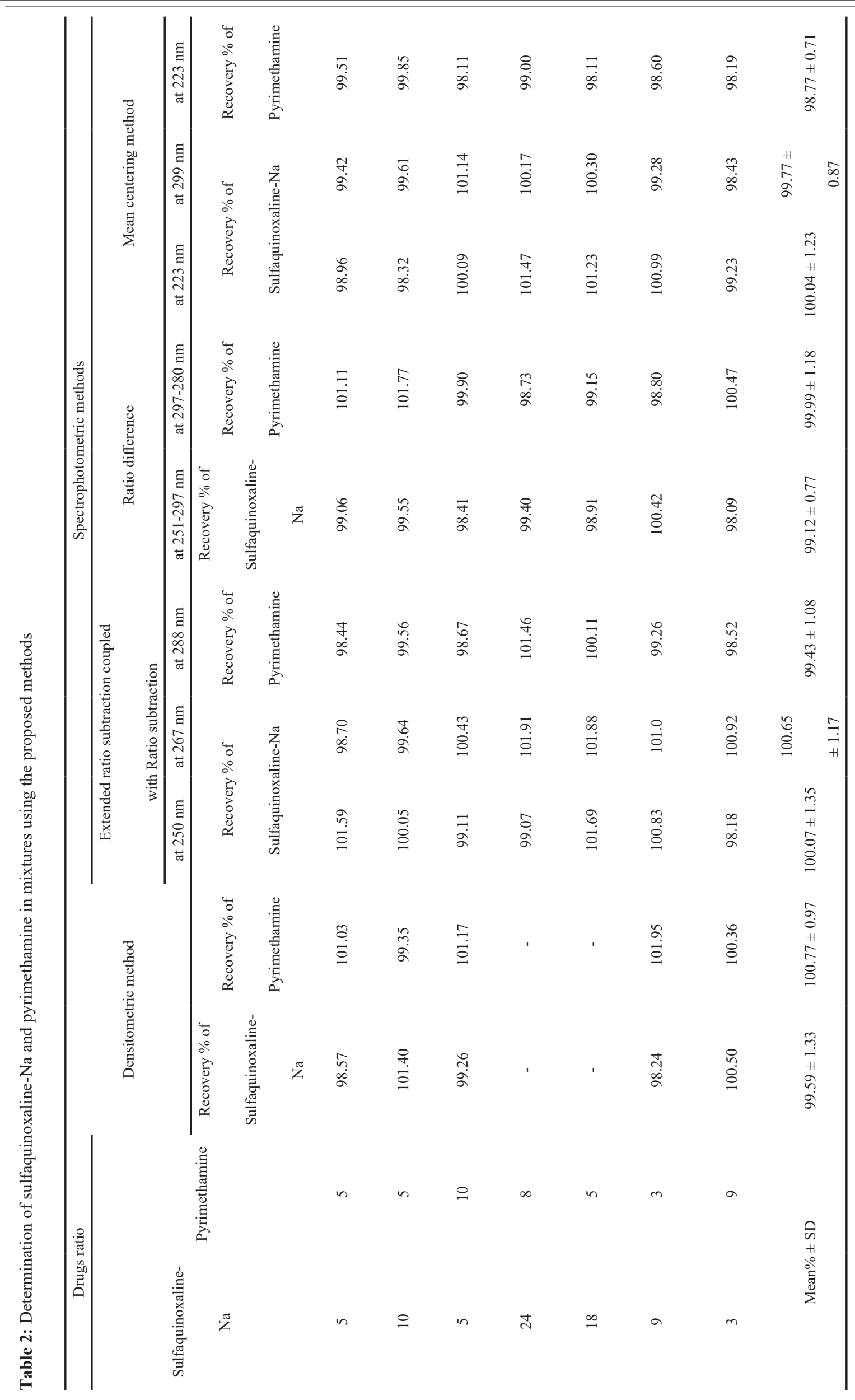




\begin{tabular}{|c|c|c|c|c|c|c|c|c|c|c|c|c|c|c|c|c|}
\hline \multirow{10}{*}{ 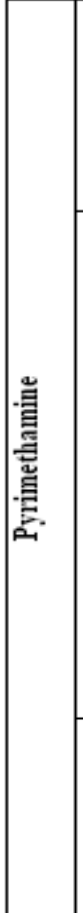 } & \multirow{2}{*}{\multicolumn{2}{|c|}{ 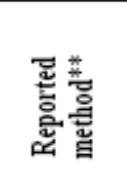 }} & \multirow{2}{*}{ 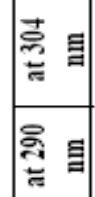 } & \multirow{2}{*}{$n$} & \multirow{2}{*}{ 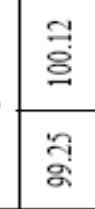 } & \multirow{2}{*}{ 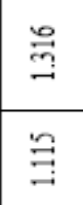 } & \multirow{2}{*}{ 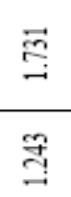 } & ' & & & \multirow{2}{*}{ 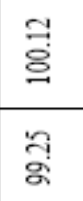 } & \multirow{2}{*}{ 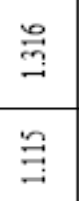 } & \multirow{2}{*}{$\begin{array}{l}\overrightarrow{\mathrm{F}} \\
\stackrel{\text { 学 }}{\mathrm{g}}\end{array}$} & ' & & \multirow{2}{*}{ ' } \\
\hline & & & & & & & & . & . & . & & & & . & . & \\
\hline & \multirow{6}{*}{ 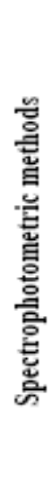 } & \multirow{2}{*}{ 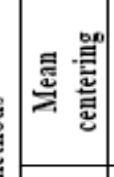 } & \multirow{2}{*}{\multicolumn{2}{|c|}{ 罡 }} & \multirow{2}{*}{. } & \multirow{2}{*}{ ' } & & & & & \multirow{2}{*}{$\begin{array}{l}\text { శี } \\
\stackrel{8}{0}\end{array}$} & \multirow{2}{*}{$\begin{array}{l}\stackrel{D}{\circ} \\
\stackrel{0}{\circ}\end{array}$} & $\infty$ & 志。 & $\underset{\sim}{\stackrel{\sim}{~}-}$ & Ḧ \\
\hline & & & & & & & & & & & & & $\circ$ & 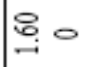 & $\overrightarrow{\mathrm{C}^{2}}$ & $@-$ \\
\hline & & 을 & 茎 & . & $\therefore$ & $E$ & 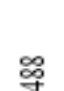 & $\frac{9}{3}{ }^{\circ}$ & $\underset{-}{-}-$ & 茫 & 里 & 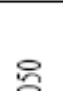 & 8 & m & $\approx$ & ${ }_{\infty}^{+1}$ \\
\hline & & $\ddot{4}$ & " & & 2 & - & i & $\mathscr{O}_{0} m$ & 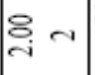 & $0^{\circ}$ & s & $=$ & - & : & $\stackrel{0}{\circ}$ & $8^{\circ}$ \\
\hline & & 올 & 吾 & & 5 & 6 & $\alpha$ & $\because 0$ & In & 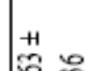 & $\Rightarrow$ & వి & $\dddot{8}$ & $\exists \infty$ & $\exists 0$ & $\stackrel{9}{g}$ \\
\hline & & 承 & 胥 & & 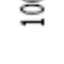 & $\because$ & 0 & 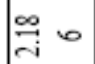 & $\stackrel{\vartheta}{\partial}+$ & $\cong-$ & 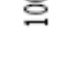 & - & & 考的 & $\vec{z} n$ & 太 \\
\hline & & E. & & 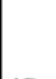 & 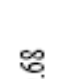 & $\stackrel{\infty}{=}$ & 5 & 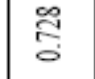 & 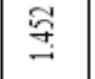 & $\stackrel{\text { 学 }}{+1}$ & ஃ & I & లి & ঐั & 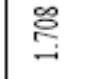 & $\stackrel{\overbrace{}}{\frac{2}{H}}$ \\
\hline & & 气ั & & 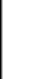 & 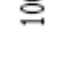 & 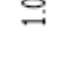 & - & 总 & 管 & तี & 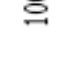 & o & 0 & 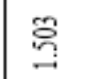 & 茎 & \\
\hline & & & 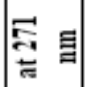 & & 옹 & ลิ & ఏ్తి & . & . & . & 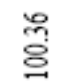 & 를 & ఏ్ & . & . & . \\
\hline & & 产 & $\underset{\Xi}{\Xi}$ 目 & & 콩 & 갈 & 23 & . & . & . & $\stackrel{3}{8}$ & 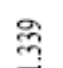 & 일 & ' & . & . \\
\hline & & & 自 & & $\circ$ & ○ & $\overrightarrow{0}$ & 志 - & $\cong+$ & م & 5 & 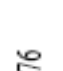 & 5 & ถิด & $\overbrace{\text { }}^{\infty} \infty$ & $\vec{a}$ \\
\hline & & 总 & : & & \% & - & - & 20 & $\stackrel{0}{\circ}$ & 8 & si & 8 & $\ddot{0}$ & పี- & Бे- & 尚 \\
\hline & & 总 & 豆 & & & & & 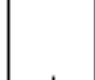 & 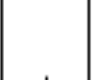 & 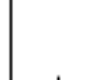 & $\therefore$ & 9 & 8 & సี่ & $\exists \infty$ & 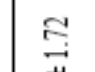 \\
\hline & 흘 & & 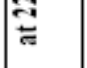 & & & & & & & & $\therefore$ & 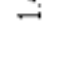 & $\sim$ & $\stackrel{9}{9}$ & $\exists \sim$ & 疍 \\
\hline 患 & 总 & .ః & $\mathrm{F}_{n}$ & & to & $\vec{b}$ & 2 & 志 - & $\exists$ & $\ddot{y}_{0}$ & ' & 우 & 8 & $\overrightarrow{\dot{O}_{0}} \infty$ & 兽 & 落。 \\
\hline 恶 & 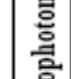 & 㫣苞 & $\underset{\substack{* \\
\hdashline}}{*}=$ & 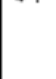 & 음 & 7 & 3 & $\vdots 0$ & $\exists$ ב & 8 & si & 0 & 0 & $m_{0}$ & $\overrightarrow{d i n}$ & 8 \\
\hline & कूँ & 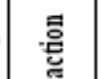 & 䓂 & & శి & J & $\therefore$ & $\Leftrightarrow-$ & 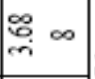 & \#ت & $\stackrel{\infty}{m}$ & 잉 & 5 & 空n & 䙲 & ') \\
\hline & & 言 & $\stackrel{\Xi}{\mathbb{E}}$ & & 음 & $\therefore$ & 0 & $\Xi-$ & $\vec{\sigma}_{i}$ in & $\stackrel{\circ}{\circ-}$ & s. & - & i & İ m & ఫి - & : \\
\hline & & 胥 & 息 & & 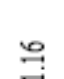 & $\infty$ & ธิ & 声。 & İn & 落 & $\Xi$ & $\therefore$ & 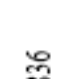 & fi: & \pm & $H_{\infty} \infty$ \\
\hline & & 岦 & 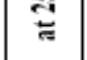 & & 음 & 0 & 0 & 20 & 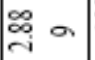 & 응 & ๙ু & 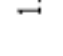 & $\rightarrow$ & - & o & ${ }^{\circ} 0$ \\
\hline & & E & & 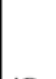 & 寸 & $\approx$ & I & $\overrightarrow{8}$ & 음 & $\underset{-1}{\stackrel{8}{+1}}$ & $\approx$ & 8 & भ & 善 & लี & $\underset{]}{]}$ \\
\hline & & 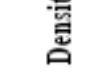 & & & 음 & - & - & 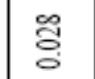 & 음 & $\overline{\mathrm{g}}$ & 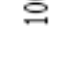 & & - & 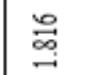 & 突 & 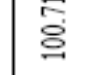 \\
\hline & S.Iכ) & atue.red & & $z$ & $\begin{array}{l}\stackrel{\circ}{\circ} \\
\text { हैँ }\end{array}$ & คे & 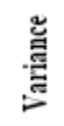 & 总 & 莺 & 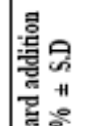 & 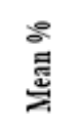 & คิ & 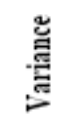 & 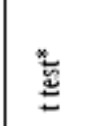 & $\begin{array}{l}\text { 莺 } \\
\text { 总 }\end{array}$ & 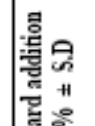 \\
\hline & иọpe & 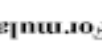 & & & & 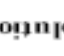 & ן.so & - & & 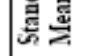 & & n'os & .000 & 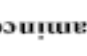 & $14 . \mathrm{L}$ & 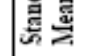 \\
\hline
\end{tabular}




\section{CONCLUSION}

Two techniques; densitometry and UVspectrophotometry had been developed for the determination of sulfaquinoxaline-Na together with pyrimethamine in their veterinary pharmaceutical formulations. The densitometric method, as a separative one, is very sensitive and consumes minimum amount of the solvents. The spectrophotometric methods were simple, employing minimum manipulation steps, rapid, precise, selective and do not need any sophisticated apparatus. Thus, the proposed methods could be successfully applied for the routine analysis of the studied drugs either in their bulk powders and in pharmaceutical formulations in quality control laboratories without any preliminary separation step.

\section{REFERENCES}

There are no conflicts of interest.

\section{REFERENCES}

1. The United States Pharmacopeia (Veterinary) 32, NF 27, Asian Ed., Rand Mc Nally, USA, 2016.

2. The British Pharmacopeia (Veterinary), Her Majesty’s Stationary Office, London, UK, 2016.

3. O'Neil M.J.; The Merck Index, fourteenth Ed, Merck and Co., Inc., Whitehouse Station, NJ, USA, 2006.

4. T.A. Catelani, I.V. Toth, J.L.F. Lima, L. Pezza, H.R. Pezza, Talanta 121 (2014) 281-287.

5. M.E.M. Hassouna, S.A.A. El-Succary, Egypt. J. Chem. 47 (2) (2004) 143-156.

6. M.H. Mohamed, S.W. Shantier, E.A. Gadkariem, International Journal of Pharmaceutical Research and Bio-Science 6 (6) (2017)16-28.

7. P. Saritha, T.C. Singh, C.G. Kumari, World J. Pharm. Pharm. Sci. 4 (09) (2015) 1077-1088.

8. A.A. Elbashir, A.H.E Elwagee, Journal of the Association of Arab Universities for Basic and Applied Sciences 11 (1) (2012) 32-36.

9. A. Soleymanpour, S.A. Rezvani, Materials Science and Engineering C 58 (2016) 504-509.

10. J.J. Berzas, J. Rodriguez, J.M. Lemus, G. Castañeda, Anal. Chim. Acta 273 (1-2) (1993) 369-375.

11. D. Orata, Y. Amir, C. Ninneza, Journal of Chemistry and Chemical Engineering 8 (2014) 215-225.

12. J.J. Berzas, J. Rodriguez, J.M. Lemus, G. Castañeda, Electroanalysis (N.Y.), 7 (12) (1995) 1156-1160.
13. N.J. Lee, C.K. Holtzapple, M.T. Muldoon, S.S. Deshpande, L.H. Stanker, Food Agr. Immunol. 13 (1) (2001) 5-17.

14. W. Haasnoot, J. du Pre, G. Cazemier, A. KemmersVoncken, R. Verheijen, B.J.M. Jansen, Food Agr. Immunol. 12 (2) (2000) 127-138.

15. T.R. Besanger, Y. Chen, A.K. Deisingh, R. Hodgson, W. Jin, S. Mayer, M.A. Brook, J.D Brennan, Anal. Chem. 75 (10) (2003) 2382-2391.

16. D. Zhang, J. Strock, J. Sherma, J. Liq. Chromatogr. Relat. Technol. 39 (5-6) (2016) 277-280.

17. F. Khuluza, S. Kigera, R.W.O. Jähnke, L. Heide, Malar. J. 15 (2016) 215-221.

18. S. Meena, S.M. Sandhya, Journal of Chemistry (2013) 6 pages.

19. L. Lugimbana, H.M. Malebo, M.D. Segeja, J.A. Akida, L.N. Malle, M.M. Lemnge, Tanzan Health Res. Bull. 8 (3) (2006) 149-154.

20. V.B. Reeves, J. Chromatogr.,-B Biomed. Sci. Appl. 723 (1-2) (1999) 127-137.

21. A. Azzouz, E. Ballesteros, J. Chromatogr.,- B Analyt. Technol. Biomed. Life Sci. 891-892 (1) (2012) 12-19.

22. A. Azzouz, B. Souhail, E. Ballesteros, Talanta 84 (3) (2011) 820-828.

23. A.P. Mantri, R. Mubeen, N. Kandepu, S. Kumar, International Journal of Pharmaceutical Sciences and Research 6 (3) (2015) 1097-1100.

24. O. Abdel-Sattar, N. EI-Abasawy, S. Abdel-Razeq, K. Abdel-Salam, N. Rashed, M. Ismail, Egypt. J. Anal. Chem. 17 (2008) 114-126.

25. P. Lakkanatinaporn, C. Matayatsuk, Songklanakarin, J. Sci. Technol. 26 (6) (2004) 849-854.

26. R.J. Maxwell, A.R. Lightfield, J. Chromatogr.,-B Biomed. Sci. Appl. 715 (2) (1998) 431-435.

27. V. Kumar, V. Sindgi, S. Satla, A. Thimmaraju, J. Appl. Pharm. Sci., 6 (03) (2016) 071-076.

28. U. Koesukwiwat, S. Jayanta, N. Leepipatpiboon, J. Chromatogr.,-A 1149 (1) (2007) 102-111.

29. J. Eljjaschewitsch, J. Padberg, D. Schurmann, B. Ruf, Ther. Drug Monit. 18 (5) (1996) 592-597.

30. H.X. Su, H.R. Tan, H.Q. Shen, C.Q. Tian, Fenxi Ceshi Xuebao 32 (2) (2013) 156-161.

31. L. Wang, J. Wu, Q. Wang, C. He, L. Zhou, J. Wang, Q. Pu, J. Agric. Food Chem. 60 (7) (2012) 16131618. 
32. R.F. Cross, A.M. Smairl, J. Chromatogr.,-A 929 (12) (2001) 113-121.

33. J.J. Berzas, J.M. Lemus, G. Castañeda, J. Pharm. Biomed. Anal. 11 (7) (1993) 601-607.

34. J.J. Berzas, J.M. Lemus, G. Castañeda, Anal. Lett. 28 (1) (1995) 93-107.

35. J.J. Berzas, G. Castañeda, F.J. Guzman, J. Chromatogr.,-A 18;870 (1-2) (2000) 169-177.

36. M.C. Ricci, R.F. Cross, J. Liq. Chromatogr. Relat. Technol. 19 (19) (1996) 3155-3171.

37. Y. Haramaki, S. Sorimachi, M. Horie, Shokuhin
Eiseigaku Zasshi 35 (3) (1994) 262-270.

38. H.M. Lotfy, M.A. Hegazy, Spectrochim. Acta A Mol. Biomol. Spectrosc. 96 (2012) 259-270.

39. E.S. El Zanfaly, A.S. Saad, A.B. Abd Elaleem, Saudi Pharm. J. 20 (3) (2012) 249-253.

40. International Conference on Harmonization; Validation of analytical procedures; Definitions and Terminology, 60, Federal Register, 1999, pp. 11260-11267.

41. D.C. Harris, Quantitative Chemical Analysis, eighth Ed., W.H. Freeman and Company, USA, Chap. 4 and 18, 2010. 